Available online at GSC Online Press Directory

GSC Biological and Pharmaceutical Sciences

e-ISSN: 2581-3250, CODEN (USA): GBPSC2

Journal homepage: https://www.gsconlinepress.com/journals/gscbps

(RESEARCH ARTICLE)

\title{
Rhizome extract of Curcuma domestica L. (Zingiberacae) in Alloxan- induced diabetic rats
}

\author{
Udobre Anieffiok Sunday ${ }^{1,}{ }^{*}$, Essien Grace Emmanuel ${ }^{2}$ and Udoh Anwanabasi Effiong ${ }^{2}$ \\ ${ }^{1}$ Department of Pharmaceutical and Medicinal Chemistry, Faculty of Pharmacy, University of Uyo, Uyo. Nigeria. \\ 2 Department of Pharmacology and Toxicology, Faculty of Pharmacy, University of Uyo, Uyo. Nigeria.
}

Publication history: Received on 20 May 2020; revised on 28 May 2020; accepted on 29 May 2020

Article DOI: https://doi.org/10.30574/gscbps.2020.11.2.0147

\begin{abstract}
Diabetes mellitus is a serious health problem in Nigeria. This study evaluated the anti-diabetic potential of Curcuma domestica in alloxam induced diabetes in albino wistar rats. In Akwa Ibom State, Nigeria the rhizome of Curcuma domestia is used in traditional medicine to expel worms from the gastrointestinal tract, relieve indigestion and frequent urination. It is also used to treat skin diseases, pains in the joints, knee, hips and spine. Rhizome of $C$. domestica was extracted using the cold solvent process. Diabetes was induced in rats and initial glucose level taken before the extract was administered and metformin also to the test animals. Blood glucose was obtained from the tail vein of the test animals in 0 hour, 1 hour, 2 hours, 3 hours, 6 hours, 12 hours, 24 hours, 3 days, and 7 days post administration, respectively. The blood glucose level was determined using a fine test glucometer. However, phytochemical screening and Chromatographic separation of the extract were carried out. The result revealed that the methanol extract of Curcuma domestica contained alkaloid, tannin, coumarin, flavonoid, terpenes, phenol, reducing sugar, and LD50 was 500 $\mathrm{mg} / \mathrm{kg}$. The result also revealed that at a dose level of $150 \mathrm{mg} / \mathrm{kg}$ the extract significantly $(\mathrm{p}<0$ 05) reduced the mean fasting glucose level from $241 \pm 0.33 \mathrm{mg} / \mathrm{dl}$ (day 0) to $56 \pm 0.31 \mathrm{mg} / \mathrm{dl}$ (day 7). The column chromatography gave 80 eluates. Eluates 49 - 67 gave the same $\mathrm{R}_{\mathrm{f}}$ value of 0.50 and was light brown in colour under UV light (254 $\mathrm{nm}$ ). The antidiabetic property of Curcuma domestica is believed to be due to the presence of bioactive bioactive constituents of the plant observed during phytochemical screening may be responsible for the anti-diabetic activity of the Curcuma domestica extract.
\end{abstract}

Keywords: Diabetes mellitus; Curcuma domestica; Blood glucose

\section{Introduction}

When we eat food that contains carbohydrate, the food digest to form glucose. The glucose stimulates the pancreas to release insulin into the blood. Insulin is the hormone that transports glucose from the blood to the cells of the body for energy. When insulin is lacking in the body, glucose will accumulate in the body. This condition is called diabetes.

There are three major types of diabetes; type 1, type 2 and gestational diabetes. In type 1 diabetes the pancreas does not produce insulin. This is because the immune system of the body mistakenly destroys the $\beta$-cells of the pancreas that produce the insulin. This condition of self- destruction is called autoimmune disease. Type 1 diabetes is also called juvenile diabetes because it occurs mostly in children. In type 2 diabetes, the pancreas produces very little insulin but the cells of the body refuse to make good use of the available insulin. Type 2 diabetes is also called adult onset diabetes because it occurs mostly in adults.

Gestational diabetes occurs in pregnant women but stops after parturition (child birth). Diabetes mellitus (DM) is defined as a fasting blood glucose level greater than $6.9 \mathrm{mMol} / \mathrm{L} .[1]$. The most popular method for the diagnosis of

\footnotetext{
* Corresponding author: Udobre Anieffiok Sunday
}

Copyright (C) 2020 Author(s) retain the copyright of this article. This article is published under the terms of the Creative Commons Attribution Liscense 4.0. 
diabetes is by measuring the fasting blood glucose (FBG). It is done in the morning. Patients with FBG greater than $125 \mathrm{mg} / \mathrm{dl}$ (11 mMol/L) are considered diabetic [2]. The management of diabetes mellitus is approached pharmacologically and non-pharmacologically. In the pharmacological approach, diabetes Mellitus is managed by the subcutaneous administration of insulin or by oral hypoglycemic agents.

The mechanism of action of oral hypoglycemic agents consists of decreasing blood sugar by stimulating pancreatic $\beta$ cells, inhibiting other hormones that elevate blood sugar, increasing the affinity and sensitivity of insulin receptors, lowering glycogen release, enhancing glucose utilization within tissues and organs clearing free radicals, resisting lipid peroxidation and improving blood circulation. The major classes of oral anti-diabetic medications include sulfonylureas, biguanides thiazolidinedione, glucosidase inhibitors, meglitinides, incretin mimetics and sodium glucose co-transporter 2-inhibitors SGLT 2 - inhibitors) [3].The non-pharmacological management entails regular monitoring of glucose level, improved daily physical exercise dietary and lifestyle modification $[3,4,5,6]$

\subsection{Statement of Research problem}

This study was designed to screen and characterize phytochemicals from rhizome extract of Curcuma domestica. It is aimed at evaluating the effect of Curcuma domestica on Alloxan induced diabetic albino rat. This may lead to the discovery of safer drugs for the treatment of diabetes mellitus or a drug that can counter the side effects of existing synthetic anti-diabetic drugs. The evaluation of anti-diabetic activity of the method rhizome extract of $C$. domestica could serve as template for the synthesis of new drugs with improved therapeutic outcome and reduced toxicity.

\subsection{The plant of study - Curcuma domestica}

Curcuma domestica belongs to the family zingiberaceae. It is a rhizome and tuberous roots with about 49 genera and 5 species. The common English name is Tumeric.. In Akwa Ibom State of Nigeria, the Ibibios call it Aran-unen while the Annang call it Asikorok. It is cultivated in India, West Pakistan, China, Malaya and West Africa. It has a yellowish coloring matter called curcuminoids, an aromatic odour and somewhat bitter taste. It also has volatile oil and the oil contains sesquiterpenes and monoterpenes [7].

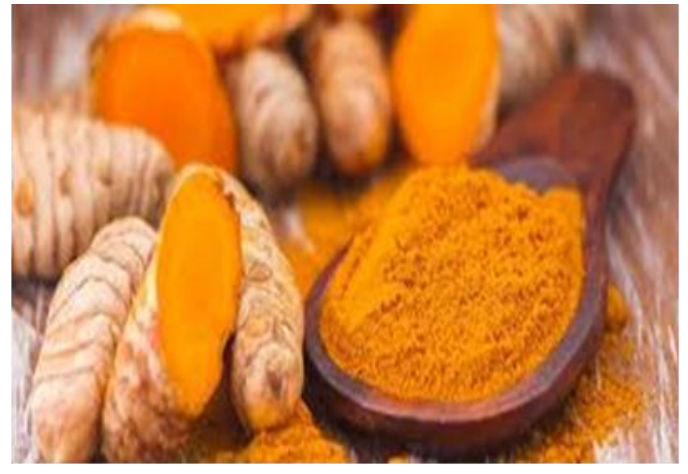

Curcuma domestica Rhizome

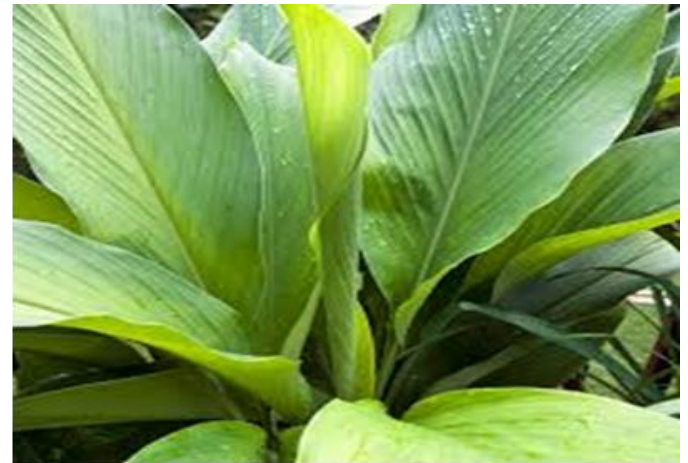

Curcuma domestica Leaf

Figure 1 Rhizome and leaf of Curcuma domestica

\subsection{Medicinal uses}

In Akwa Ibom State, Nigeria, the rhizome of Curcuma domestica is used to treat jauandice, skin diseases, pains in the joints, knee, hips and spine. It relieves indigestion, increases bile flow, prevents blood clotting, cholesterol formation, gall stone and expels worms from the gastro intestinal tract. The yellow dye from the rhizome is used to colour the skin, poultry, rice and pork. The rhizome paste is used to treat psoriasis and athletes foot [ 8]. Rhizome of Curcuma domestica was found to have potential effect in controlling osteoarthritis, inflammation, thrombosis, oxidative stress and microbial activities [9].

\section{Material and methods}

\subsection{Identification and Collection of Plant Materials}

The fresh root ( $1 \mathrm{~kg}$ ) of Curcuma domestica was bought from Itam market Akwa Ibom State, Nigeria. This plant was identified and authenticated as Curcuma domestica Linn, by Prof. (Mrs.) Margret Bassey of the Department of Botany 
and Ecological Studies, University of Uyo and was deposited in the University of Uyo herbarium, Department of Pharmacognosy and Natural Medicine, Faculty of Pharmacy.

\subsection{Preparation of Root / Rhizome}

The plant root was cut into smaller size and air-dried, pulverized using grinder (mortar). $400 \mathrm{~g}$ of the powder was weighed and cold-macerated for 72 hours with methanol ( $5 \mathrm{~L}$ ). The extract was evaporated to dryness using Rotary evaporator.

The concentrated extract was dissolved in Methanol; the dissolved mixture was successfully partitioned with n-hexane and Chloroform to yield their respective fractions. These fractions were concentrated by evaporating to dryness, and the resulting fraction stored at $-4^{\circ} \mathrm{C}$ in the refrigerator until required for Anti-diabetic study and phytochemical screening.

\subsection{Phytochemical Screening of the Rhizome extract of Curcuma. domestica}

was carried out using the standard Method [7,9].

\subsection{Chromatographic Separation}

An open glass column with $30 \mathrm{~mm}$ diameter and $500 \mathrm{~mm}$ long was used. A plug of cotton wool was pushed to the bottom of the column and silica gel of mesh size 60 - 120 was constituted into slurry with n-hexane and poured into the column with n-hexane to cover the adsorbent. Another plug of cotton wool was then introduced into the column about $10 \mathrm{~mm}$ away from the slurry.

$2.0 \mathrm{~g}$ of the dry Methanol extract was triturated with $10 \mathrm{~g}$ of silica gel to form a paste. The mixture (paste) was loaded into the column to rest on the plug of cotton wool and more of the solvent (n-hexane) was introduced into the column using a funnel till it covers plant material.

The column was eluated with chloroform:methanol solvent system. The thin layer chromatography was used to monitor the outcome.

\subsection{Thin Layer Chromatography (TLC)}

Pre-coated aluminum foiled TLC plate of dimension $(4 \times 10 \mathrm{~cm})$ were marked and labeled appropriately. Chloroform and methanol (9:1) were used as the solvent system. The solvent system was poured into the TLC tank and the tank was covered and shaken to ensure proper mixing. The tank was left to stand for 10 minutes for adequate saturation. The column chromatography was spotted accordingly on the pre-mark plates using capillary tube, allowed to develop The spotted plates were then introduced into the already saturated tank, and the tank covered, allow standing for development. The plate were removed as the solvent reached the solvent front on the plate and air - dried, thereafter the TLC plates were detected using ultraviolet (UV) light at wave-length $254 \mathrm{~nm}$ and also heated in the oven at $150{ }^{\circ} \mathrm{C}$ for 4 minutes to review the spot. The retention factor $\left(\mathrm{R}_{\mathrm{f}}\right)$ for each spot was calculated using the formula

$$
R_{f}=\frac{\text { Distance from centre of spot to origin }}{\text { Distance from solvent front to origin }}
$$

\subsection{Experimental Animals}

Healthy Wistar albino rats between two and four month of age and weighing 100 - 150g will be used for the study. They will be purchased from the Animal House of the Department of pharmacology and Toxicology, University of Uyo, Uyo, Akwa Ibom States, Nigeria.

\subsection{Ethical Approval}

Approval for the use of the animals for the study was obtained from The Animal Ethics Committee of the Faculty of Pharmacy, University of Uyo. All Animal experiments were conducted in accordance with Internationally accepted Laboratory Animal use and care of Laboratory Animals (1966) as adopted and promulgated by the National Institute of Health ( N.I.H) Publication Number 8523 Revised 1996 based on the Hensinki Convention.

The rats were acclimatized in different (standard laboratory animal cages (six per cage) for 7 days. The animals were maintained under good laboratory practice of 12 hours light and 12 hours dark cycle at a uniform temperature of 28 。 $\mathrm{C}$. All animals were given free access to food (growers' marsh, Pfizer, Kaduna) and water (ad libitum). All investigations 
involving the experimental animals were conducted in accordance with the accepted principles for laboratory animal use and care.

\subsection{Animal grouping and Alloxan Induced Diabetes Model}

Alloxan monohydrate (Sigma Aldrich, Germany), was used to cause pharmacological diabetes to confirm the effectiveness of methanol extracts of $C$. domestica in experimental diabetic conditions. Diabetes was induced in 30 albino rat by injecting $150 \mathrm{mg} / \mathrm{kg}$ of Alloxan monohydrate intraperitoneally dissolved in $0.9 \% \mathrm{w} / \mathrm{v}$ cold normal saline to overnight-fasted rat (12 h). The rats were afterwards kept for the next $24 \mathrm{~h}$ on $10 \%$ glucose solution bottles, in their cages, to prevent hypoglycemia. After $72 \mathrm{~h}$ of injection, fasting blood glucose level was measured. The animals that did not develop more than $200 \mathrm{mg} / \mathrm{dL}$ glucose levels were omitted from the study.

Thirty (30) selected diabetic rat were divided into five groups of six rats per group $(n=6)$.

Group 1 served as negative control and was treated with $1 \mathrm{ml}$ distilled water orally fed using a feeding tube. Group 2 had alloxan induced diabetes and was treated with metformin $(7.14 \mathrm{mg} / \mathrm{kg} /$ day) as the reference drug every morning. Groups 3, 4, and 5 had alloxan induced diabetes and were given 50, 100, and $150 \mathrm{mg} / \mathrm{kg}$ per day C. domestica doses, respectively. The animals were given the extracts once every morning by compulsory oral intubations before meals. The treatment was continued for seven (7) consecutive days.

\subsection{Collection of Blood Samples for Glucose Analysis}

Blood samples for glucose analysis were collected from the tail vein of the over night fasted rats (12 h) after 3 days of administration of Alloxan (day 0) and subsequently on days 1, 3 and 7 The first blood drop was wiped away but the second was dropped onto a glucose strip in the Fine Test glucometer (Roche Diagnostics, Germany), to get a glucose reading. The tails were then rubbed with ethanol to prevent infection.

\subsection{Data and Statistical Analysis}

Data are reported as the mean \pm SEM of triplicate determinations. Statistical analyses were performed using Graph Pad Prism version 5.0 for Windows. One - way ANOVA was used to test for variation in pharmacological activity among the treatment groups, and $\mathrm{p}<0.05$ was considered to represent a statistically significant different between test populations.

\section{Results}

Table 1 Antidiabetic effect of methanol extracts of Curcuma domestica on blood glucose levels of alloxan-induced diabetic rats for 7 days treatment.

\begin{tabular}{llllll}
\hline $\begin{array}{l}\text { Treatment } \\
\text { Days }\end{array}$ & $\begin{array}{l}\text { Negative } \\
\text { Control }\end{array}$ & $\begin{array}{l}\text { Positive } \\
\text { Control }\end{array}$ & $\begin{array}{l}\mathbf{5 0} \text { C.domestica } \\
\mathbf{m g} / \mathbf{k g}\end{array}$ & $\begin{array}{l}\mathbf{1 0 0} \mathbf{\text { C.domestica }} \\
\text { C. do }\end{array}$ & $\begin{array}{l}\mathbf{1 5 0} \mathbf{\text { mg/kg }} \\
\text { C.domestica }\end{array}$ \\
\hline 0. & $369 \pm 0.33$ & $450 \pm 0.46$ & $363 \pm 0.60$ & $281 \pm 0.34$ & $241 \pm 0.33$ \\
1. & $158 \pm 0.27$ & $79 \pm 0.00$ & $108 \pm 0.01$ & $91 \pm 0.02$ & $148 \pm 0.01$ \\
3. & $235 \pm 0.31$ & $64 \pm 0.01$ & $78 \pm 0.01$ & $135 \pm 0.01$ & $78 \pm 0.00$ \\
7. & $205 \pm 0.23$ & $101 \pm 0.03$ & $110 \pm 0.21$ & $97 \pm 0.00$ & $56 \pm 0.31$ \\
\hline
\end{tabular}




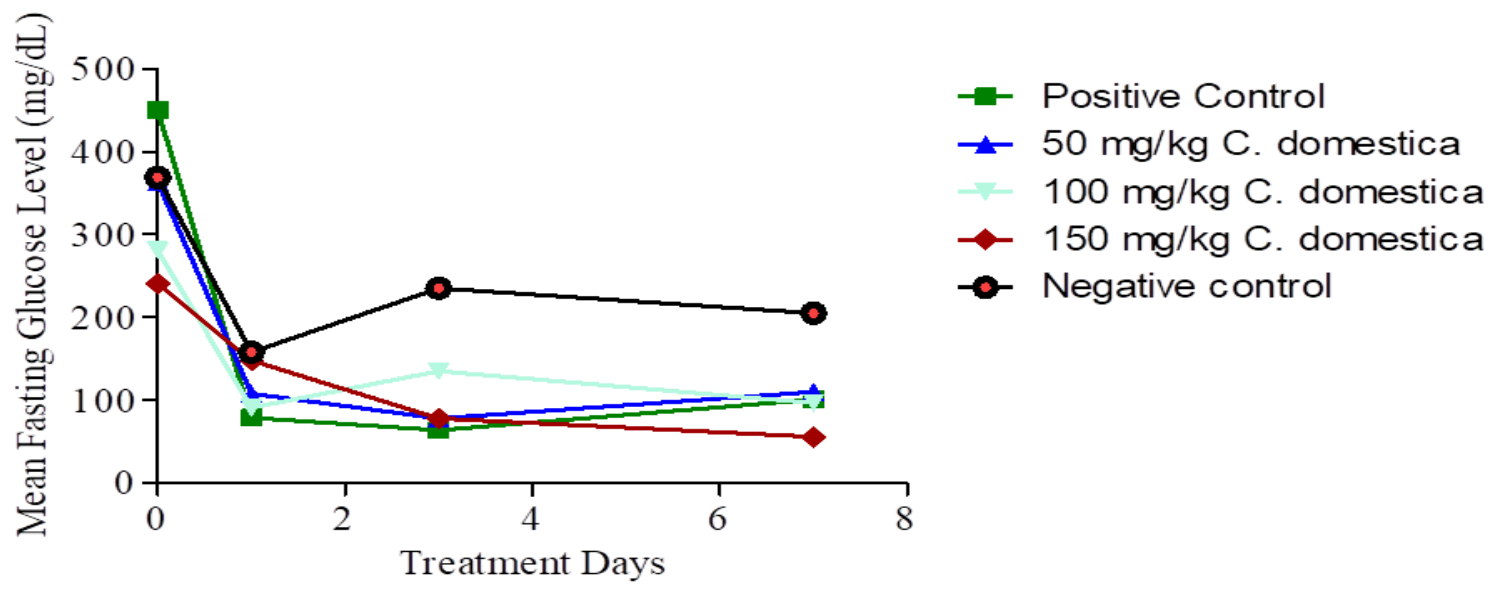

Figure 2 Antidiabetic effect of methanol extract of Curcuma domestica on blood glucose levels of alloxan-induced diabetic rat for 7 days treatment. Data is expressed as Means \pm SEM and treatments were compared using One - Way ANOVA.

The methanol extract showed a non-dose dependent reduction in the glucose level. At a dose of $150 \mathrm{mg} / \mathrm{kg}$, C. domestica showed a better hypoglycemic activity relative to the standard drug.

Table 2 Phytochemical Screening of Methanol Extract of Curcuma domestica.

\begin{tabular}{lll}
\hline Phytochemicals & Observation & Presence \\
\hline Alkaloid & Orange-brown colour & + \\
Saponins & Persistent frothing & + \\
Tannin & Yellow & + \\
Coumarin & Yellow & + \\
Flavoniod & Deep brown ppt & + \\
Terpenes & Red colour & + \\
Phobatanins & Green ppt & + \\
Cardiac glycosides & Reddish brown & + \\
Phenol & Deep blue ppt & + \\
Anthraquinone & Pink colour & + \\
\hline & Key: + = Presence; - = Absence &
\end{tabular}

\section{Discussion}

The results of the phytochemical screening revealed that alkaloid, coumarin and reducing sugar were present in the Curcuma domestica. This results agreed with the worK done by Neha et al (2013) [9]

Alloxan induces diabetes by generating reactive oxygen species (ROS). This ROS are free radicals that destroy the $\beta$-cells of the pancreas that produce insulin. Lack of insulin leads to hyperglycemia $[10,11]$.

The results of the anti-diabetic study showed that the daily doses of Curcuma domestica extract significantly $(\mathrm{P} \leq 0.05)$ reduced the mean blood glucose levels compared to the negative control. One possible explanation for this could be the presence of anti-oxidant in the plant extract. Antioxidants inactivate ROS which cause cell damage [12]. 
According to Petchi [13] favonoids regenerate the damaged beta- cells of the pancreas. It is therefore possible that Curcuma domestica leaf extracts may have caused the reduction in the mean fasting Glucose level by regenerating the $\beta$-cells of the pancreas, potentiating insulin secretion from the surving $\beta$-cells and increasing peripheral glucose uptake and utilization. $[14,15]$

\section{Conclusion}

The findings from this research revealed that the methanol extract of Curcuma domestica contained bioactive phytochemical agents such as flavonoids and alkaloids is useful in controlling elevated blood glucose level. The extract also significantly reduced the blood glucose level in the rat compared to the negative and positive control.

\section{Compliance with ethical standards}

\section{Acknowledgments}

The technical advice of Dr. Aniekan Ebong and Mrs Akaninyene Emmanuel Akpan is highly appreciated.

\section{Disclosure of conflict of interest}

All author's declare no conflict of interest is exist.

\section{Statement of ethical approval}

Approval for the use of the animals for the study was obtained from The Animal Ethics Committee of the Faculty of Pharmacy, University of Uyo

\section{References}

[1] Zimmet P, Cowie C and Jonathan S. (2004). Classification of Diabetes Mellitus and other Categories of Glucose Intolerance.International Text book Diabetes Mellitus. John Wiley and Sons, Ltd, New York, USA.

[2] Abiola D, Sathyapalam T and Hepburn D. (2016). Management of type 1 and type 2 diabetes requiring insulin. Prescriber, 27(9), 50-57.

[3] Piero N, Murugi N, Mwiti K and Mwenda M. (2012). Pharmacological Management of Diabetes Mellitus. Asia Journal of Biochemical and Pharmaceutical Research, 2(2), 375-381.

[4] Mooradian D, Miller M, Dobs B and Gibson M. (2007). The Effect of Selected Nutrients on Serum High-density Lipoprotein Cholesterol and Apolipoprotein A-1 Levels. Endocrine Reviews, 27, 2-16.

[5] Inzucchi S and McGuire K. (2008). New Drugs for The Treatment Diabetes: part 11: Incretin-based therapy and beyond. Circulation, 117(4), 574-584.

[6] Ranjan A. (2018). Glucagon Treatment in Type 1 Diabetes. Danish Medical Journal, 65(2), B5449.

[7] William C. (2009). Treas and Evans pharmacognosy text book. Saunders Elsevier, London, 16, $42-494$.

[8] Etukudo Inyang. (2003). Ethnobotany: Conventional and Traditional Uses of Plants. The Verdic Press. No. 20 Akpakpan Street, Uyo, Akwa Ibom State, 133.

[9] Neha A. (2013). Phytochemical Screening of Extract fromC. domestica.Journal of medicinal plants, 2(7), 113 - 118.

[10] Stanely P, Prince M and Menon P. (2000). Hypoglycaemic and Other Related Actions of C. domestica roots in Alloxan-induced Diabetic rats. Journal Ethnopharmacoloyg, 70, 9-15.

[11] Bajaj S and Khan A. (2012). Antioxidants and diabetes. Indian Journal Endocrinol. Metabolism, 16, $267-271$.

[12] Joseph A, Theophilus C, Dominic A, Rita A, Kwaw L and Kofi A. (2013). Anti-hyperglycemic and Antioxidant Effects of $C$. domestica (Zingiberaceae) in streptozotocin-induced diabetic rats. African Journal Tradition Complement Alternative Medicine, 10, 386-393.

[13] Petchi R, Parasuraman S and Vijaya C. (2013). Antidiabetic and Anti-hyperlipidemic Effects of an Ethanolic Extract of the whole Plant of $C$. domestica (Linn.) in Streptozotocin-induced Diabetic rats. Journal Basic Clinical Pharmacy 4, 88-92. 
[14] Kirpichnikov D, McFarlane I and Sowers R. (2002). Metformin in Management of Type 2 Diabetes. Annals of Internal Medicine, 137(1), 25-33.

[15] Graham R, Hardie G and Pearson E. (2017). The Mechanisms of Action of Metformin. Diabetologia, 60(9), 15771585.

\section{How to cite this article}

Udobre AS, Essien GE and Udoh AE. (2020). Rhizome extract of Curcuma domestica L. (Zingiberacae) in Alloxan- induced diabetic rats. GSC Biological and Pharmaceutical Sciences, 11(2), 327-333. 